\title{
Perceptions and Experiences of Infant Massage among Caregivers of Infants 2-6 Months Old Consulting at Two Public Health Centers in Quezon City, Philippines, before and after Infant Massage Training
}

\author{
Cynthia P. Cordero, MScPH, MMedStat,, ${ }^{1,4}$ Maria Teresa S. Tolosa, MD, Diploma Clin. Epi., ${ }^{1,2,3}$ \\ Mikarla M. Lubat, RND, ${ }^{4}$ Rio May E. Llanes, MD, ${ }^{4,5}$ Abraham C. Hermoso, MD, ${ }^{4}$ \\ Constantine L. Yu Chua. MD, ${ }^{6}$ Demi Arantxa C. Sepe, RN ${ }^{4}$ and Lailanie Ann C. Tejuco, LPT $^{7}$ \\ ${ }^{1}$ Department of Clinical Epidemiology, College of Medicine, University of the Philippines Manila \\ ${ }^{2}$ University of the East Ramon Magsaysay Memorial Medical Center, Inc. (UERMMMCI) \\ ${ }^{3}$ St. Luke's Medical Center - College of Medicine, William H. Quasha Memorial (SLMC-CM WHQM) \\ ${ }^{4}$ Foundation for the Advancement of Clinical Epidemiology, Inc. \\ ${ }^{5}$ Department of Internal Medicine, Chong Hua Hospital \\ ${ }^{6}$ Department of Psychiatry and Behavioral Medicine, Philippine General Hospital, University of the Philippines Manila \\ ${ }^{7}$ Institute of Clinical Epidemiology, National Institutes of Health, University of the Philippines Manila
}

\begin{abstract}
Background. The benefits of infant massage in hospital and community settings have been documented in literature: better weight gain of preterm and low birthweight infants, shortened hospital stay, slightly better scores on developmental tests, fewer postnatal complications, and effects on physical and mental health.
\end{abstract}

Objectives. This study described the perceptions and experiences of infant massage among caregivers of infants 2-6 months old consulting in two public health centers in Quezon City before and after infant massage training.

Methods. This qualitative study assessed perceptions and experiences at baseline and after infant massage training of mothers and caregivers taking care of infants 2-6 months old. Pre-training interviews were conducted, as well as immediately after, and seven days after training on infant massage delivered by the Philippine League of Government and Private Midwives, Inc. (PLGPMI). Training consisted of lectures and demonstrations, after which mothers/ caregivers gave their babies the massage under the trainer's supervision. Post-training interviews were conducted immediately after the training and seven days after. Responses to the interviews were transcribed. The transcripts and interview notes were analyzed independently by two research team members. Qualitative Content Analysis (QCA) was done. Disagreements were settled by discussion.

Results. The infant's mother was identified as the best person to perform infant massage. Infant massage was a new concept to many participants before the training. In general, the perception was positive. It was believed to promote the baby's physical development and bonding with the mother/caregiver. These same benefits were reported after the training. Post-training, all 11 participants who returned for follow-up interviews reported having massaged their babies at home. They were also able to describe the process and timing of massage as taught to them. The participants' responses centered on seven (7) identified themes, identified at baseline and after training: 1) general concepts of infant massage, 2) benefits of infant massage, 3) methodologies, materials, and considerations, 4) persons credible to perform infant massage, 5) application/performance of infant massage, 6) intentions and 7) infant massage as a public health measure.

Corresponding author: Cynthia P. Cordero, MScPH, MMedStat Department of Clinical Epidemiology

College of Medicine

University of the Philippines Manila

Rm. 103 Paz Mendoza Bldg.

547 Pedro Gil St., Ermita, Manila 1000, Philippines

Email: cpcordero@up.edu.ph
Conclusion. There was a positive perception of infant massage among mothers and caregivers of infants 2-6 months old, whether or not they had prior knowledge. The sharing of information and the training given enhanced this. Participants showed good reception and retention of infant massage's basic concepts and 
process and improved their confidence in handling their babies and massaging them.

Keywords: infant massage, mother-child relations, caregivers (Filipino caregivers), health education, community health centers, parent training

\section{INTRODUCTION}

The practice of infant massage has been widely observed in many cultures across the globe. In many parts of Asia, traditional mothering has involved infant massage, passed down for generations. ${ }^{1}$ In Western societies, the onset has been much later. Among the contexts in which it was first introduced were preterm infants in the stressful, sterile setting of the neonatal intensive care unit where human touch was limited or missing. ${ }^{2}$ There are several potential mechanisms by which touch could benefit human infants.

High cortisol concentration was posited to cause damage to the young brain and reduce the ability of babies to regulate stress levels. ${ }^{3}$ High cortisol was found to be attenuated by infant massage, and the latter also lowered the levels of norepinephrine and epinephrine. ${ }^{4}$ As offered by Vickers et al., the effect of infant massage on growth is tied to the secretion of insulin and gastrin, events that improve absorption of food. ${ }^{2,5}$ Improvement in sleep is attributed to the release of melatonin. ${ }^{6}$

Vickers et al. showed that in preterm and low birth weight infants, those given infant massages had better weight gain, shortened hospital stay, slightly better scores on developmental tests, and fewer postnatal complications. ${ }^{2}$ A formal review of studies on massage therapy done in the Philippines in 2003 cited weight gain for preterm infants, reduced infant response to pain after a heel-stick procedure, and reduced stress hormones among critically-ill infants and children as possible benefits of infant massage. ${ }^{7}$

Bennett et al. did a systematic review and metaanalysis of massage interventions to promote mental and physical health in normally-developing infants below six months old. ${ }^{8}$ Results showed that for normally-developing infants, the impact of massage might vary, evidenced by the heterogeneity of effects on physical and mental development. The cited variability stemmed from differences in settings, diversity of the usage of infant massage across various settings, massage providers, and methodologic quality. The environment of the studies varied widely, as there were 16 studies conducted in the community after training on infant massage, three in a school/day-care center/orphanage, and two in hospitals. For 13 studies, the setting was unclear. The authors also noted that many of the studies (20 out of 34) had a high risk of bias.

Several studies included in the systematic review were done in the community in Asian and Eastern countries. For instance, the study of Argawal et al. in India investigated if massage using commonly-used oils in the community was beneficial for infants. ${ }^{9}$ A total of 125 infants were randomized to be massaged with different oils (herbal oil, sesame oil, mustard oil, or mineral oil) every day for four weeks. There was a group of infants who did not receive massage and was designated as control. The study showed that the group massaged with sesame oil showed significant growth benefits (i.e., length, midarm circumference, and midleg circumferences). All massage groups had significantly better post-massage sleep duration, which was highest in the sesame oil group. ${ }^{9}$

Ferber's community-set study in Israel involved 21 dyads of mothers and full-term infants; the parents were trained to perform massage on the babies. ${ }^{6}$ Babies received either daily massage for two weeks or no treatment. The researchers sought to evaluate the effect of massage therapy on melatonin secretion rhythms to nighttime and phase adjustment of rest-activity. It was shown that at 12 weeks of age, there were significantly higher levels of nocturnal 6-sulphatoxymelatonin in the massaged infants. ${ }^{6}$ The authors concluded that during the perinatal period, massage therapy by mothers helped establish a time cue for babies, assisted in developing the circadian system in coordinating with environmental cues.

The 2007 study of Jing et al. in China, set in the community, involved the parents of infants in massage and motion training through manuals and video compact disc (VCD). ${ }^{10}$ In the experimental group, massage and motion training were done for 15 minutes once or twice a day, from 0-6 months. The control group received no such massage. Results showed that at six months of assessment, the babies who received massage and motion training in the newborn period were longer and weighed more than those not massaged..$^{10}$ At the same attained age, the experimental group's developmental quotient (DQ) was significantly higher than that of the control group. This was sustained at the follow-up at age one year.

Overall, among the outcomes for which meta-analyses were performed, there was a significant benefit of infant massage for length, head circumference, arm and leg circumference, 24-hour sleep duration, time spent crying/ fussing, decreased levels of blood bilirubin, and fewer cases of diarrhea. ${ }^{8}$

The included studies and the derived results brought the authors of the review to conclude that infant massage may not be recommended for low-risk settings of infants and their parents. The authors, however, recognized that the effect of infant massage depended a lot on factors such as the manner, frequency, and duration of delivery of the massage. ${ }^{8}$ A study of infant massage programs identified infant cues, setting, and parent-child interaction as essential mechanisms to be considered. ${ }^{11}$ The study also noted that the most likely parent/caregiver-infant dyads to benefit from infant massage were those who were moderately at risk of lacking adequate interactions, who were "demographicallyor socially-deprived." ${ }^{11}$ This is a common situation in the 
Philippines where mothers, or parents in general, are forced to work away from their families due to better opportunities abroad. Parents, in this case, can identify caregivers who can be trained how to perform infant massage in their absence, as the domestic set-ups usually include members of the extended family. Even mothers/caregivers who are full-time domestic homemakers may run the risk of inadequate tactile connection with their babies when they prioritize the challenges of housework. In this light, their infants might represent a subset that stands to benefit from massage optimally.

Access to infant massage training opportunities is, notably, limited in the Philippines. Several descriptions of how to perform infant massage are available on the Internet. ${ }^{12}$ There are also video demonstrations on how to perform infant massage. Internet-based resources, however, lack the personal touch that infant massage training sessions are expected to have. More formal training is available at the Nurturing Touch Therapeutic Play Clinic located in Makati City, National Capital Region. ${ }^{13}$ Training is offered in-class setting and individual instruction by an infant massage practitioner accredited by the International Association of Infant Massage (https://www.iaim.net/). The IAIM curriculum is an intensive training that requires visits to the clinic by mother/caregiver-infant dyads for several days. As such, it is offered to a limited number of participants at a time. The required visits and fees may also not be feasible for most Filipino families.

Infant massage entails minimal expertise, technology, costs, and risks, yet may represent a significant well-being source among babies. ${ }^{8}$, Benefits to the caregivers have been reported as well. In a cohort study in Portugal, mothers who learned how to perform infant massage had more positive attitudes towards the experience of motherhood compared to those who did not. They were more adjusted to motherhood and were more confident in their abilities. ${ }^{14} \mathrm{~A}$ central theme emerged in a qualitative study in Norway of 12 mothers who struggled postpartum and joined an infant massage training. Infant massage was "a relief, with an opportunity for emotional and physical connection with the baby." ${ }^{15}$ Mothers' experiences include themes that were categorized as (1) appreciating the structure of the training, (2) providing self-esteem and self-confidence, (3) connecting with the baby, and (4) discovering the baby's presence. ${ }^{15}$

It may be worth introducing infant massage to mothers/ caregivers in the community through public health centers. As with any health promotion activity, success lies in awareness, a favorable attitude, and positive experience among stakeholders. For infant massage, mothers and other caregivers of infants are essential stakeholders.

This study described the perceptions and experiences of infant massage among mothers/caregivers of 2-6-monthold infants consulting at two public health centers in Quezon City before and after they were introduced to infant massage.

\section{MATERIALS AND METHODS}

\section{Research Design, Setting, and Recruitment of Participants}

This is a qualitative study that assessed perceptions and experiences at baseline and after infant massage training of mothers and caregivers taking care of infants 2-6 months old, who consult at Commonwealth Main and Payatas B health centers in Quezon City

With the help of health center staff and City Health Workers (CHWs), dyads were recruited according to the following inclusion criteria:

1. Mothers/caregivers consulting in Commonwealth Main and Payatas B health centers who are taking care of a) term, normally-developing infant, or b) term but low birth weight infant, or c) preterm infant

2. The mother/caregiver gave informed consent to participate in the study.

Dyads with the following conditions were excluded from the study:

1. Medically unstable infants ${ }^{16-19}$ including those with
a. congenital heart malformation
b. gastrointestinal disorders
c. central nervous system disturbances
d. congenital anomalies
e. HIV positive
f. infants requiring surgery
g. infants with mothers that have reported maternal drug addiction
h. respiratory distress
i. sepsis and other infections

2. Infants with broken skin, as the lesion or compromised area, should not be directly touched. Other locally contraindicated skin conditions like bacterial, fungal, and viral infections and other skin disorders, including but not limited to herpes and varicella, measles, mumps and rubella, warts, contact dermatitis and hives, atopic dermatitis, seborrheic dermatitis, and other eczematous disorders, and psoriasi $\mathrm{s}^{20}$

3. Infections such as cellulitis, impetigo, furunculosis, carbuncles, abscesses ${ }^{19}$

4. Skin conditions such as lice, scabies, and mites ${ }^{19}$

A total of 20 mother/caregiver-infant dyads (10 per facility) were targeted. City Health Workers (CHWs) nominated dyads from their catchment area to fit the inclusion and exclusion criteria. CHWs regularly monitor families and households in their area and were considered the best health worker to nominate dyads. Using the health center's records, a health center's health provider checked the eligibility of the dyads selected by the CHWs. A list of potential participants was prepared. 


\section{Baseline Interviews}

Potential participants were invited to the health centers, and interviews were conducted after informed consent was obtained. The discussions were guided by questions to determine perceptions and experiences of study participants (Table 1). On follow-up, respondents were also asked about their perceptions of the training that they attended. After the interview, participants were examined by the medical officer of the health center. Dyads who fulfilled all inclusion criteria and did not have any exclusion criteria were invited to the training on infant massage.

\section{Training on infant Massage and post-training interviews}

The training was conducted by an infant massage practitioner/instructor from the Philippine League of Government and Private Midwives, Inc (PLGPMI). The session started with a short lecture, followed by a dummy baby demonstration, and ended with a supervised hands-on session.

The lecture included general information about infant massages, such as their benefits, precautions, and contraindications. Then the method described by Field was introduced. ${ }^{21}$ Field's massage therapy involves both tactile and kinesthetic stimulation. Massage is rendered in 15-minute sessions: five minutes of tactile stimulation to start, five minutes of kinesthetic stimulation, and ending after another five minutes of tactile stimulation. Three massage sessions have to be given to the baby every day.

In the phase of tactile stimulation, the infant is placed prone and given moderate pressure stroking using the flats of the fingers of both hands. Five repeats of one-minute intervals, consist of six periods of stroking, ten seconds long, applied to the following regions:

a. from the top of the infant's head, down the back of the head to the neck and back to the top of the head;

b. from the back of the neck across the shoulders and back to the neck;

c. from the upper back down to the buttocks and returning to the upper back (avoiding contact with the spine);

d. simultaneously on both legs from the hips to the feet and back to the hips;

e. both arms simultaneously from the shoulders to the wrists to the shoulders.
In the kinesthetic phase, the infant is positioned in the supine position. The five one-minute segments involve six passive flexion-extension movements that last about ten seconds each. These "bicycling-like" movements of the limbs are done in this sequence: (a) right arm, (b) left arm, (c) right leg, (d) left leg, and (e) both legs simultaneously.

The trainer then demonstrated how to perform Field's method of infant massage using a dummy baby. After all, questions were answered, mothers/caregivers performed infant massage on their babies under the instructor's supervision. Printed training materials, mats, and enablers were provided. The training lasted for half a day. Fans containing the description of Field's method of infant massage were given to the participants as tokens. Lunch was served, and posttraining interviews were conducted. During the follow-up interviews seven days after the training, mothers were asked about their experiences with the exercise, infant massage and whether or not they performed it.

\section{Data management and analysis}

Data were transcribed verbatim from audio recordings. Notes by interviewers were also used to complement the transcribed recording. Qualitative Content Analysis (QCA) was done. Two research team members independently examined the transcripts, coded the interview transcripts, and developed themes on perceptions and experiences of caregivers of infant massage to ensure reliability. The themes identified by both analysts formed the initial list of themes. The second analyst considered themes identified by only one analyst for inclusion by referring to the codes and transcripts. The resulting themes were then presented to the rest of the research team for feedback. Disagreements were settled by discussion. Frequencies of answers to categorical questions were presented to support the derived themes.

\section{Ethical Considerations}

The University of the Philippines Manila Research Ethics Board (UPMREB) approved the protocol and related documents. Informed consent, voluntary participation, protection of participants was upheld. The study, funded by Johnson and Johnson Philippines, Inc., was declared a conflict of interest. Enablers and tokens given to the participants were a mix of products from various manufacturers. The company's participation was limited to monitoring the study progress.

Table 1. Topics covered in the semi-structured interviews at baseline, immediately, and 7 days after the training

Perceptions

- Understanding of and sources of information about infant massage

- Benefits of infant massage

- Description of how infant massage is done

- The best person to perform infant massage

- Appropriate age of infant for massage

- Other considerations for infant massage

- Reasons for agreeing or continuing to perform infant massage

\section{Experiences and Intentions}

- Experience with infant massage

- Reasons for massaging one's baby during infancy

- Description of experience of infant massage

- Changes observed on the baby during massage

- Intention to give infant massage if they will have another child

- Recommendation of infant massage to other mothers/caregivers

- Reasons for participating in an opportunity to learn infant massage

- Opinion on infant massage as one of the programs at the health center 
Only mothers/caregivers who gave informed consent were included in the study. After the background, objectives, and study methods were explained to potential participants, they were asked if they have questions. Mothers/caregivers were asked to sign the informed consent form only after their questions were answered. During the consent process, participation was emphasized as voluntary and that they can withdraw their participation at any time. Informed consent was obtained before every interview. An audio recording was done only after the mother/caregiver gave permission.

Using the medical records of the health centers and performing a physical examination, all potential dyads were screened by the medical officer (MO) of the health centers before the training. On the day of the training, the MO performed a second screening. Only mother-infant and caregiver-infant dyads who fulfill the inclusion and exclusion criteria of the study were included in the study. Dyads found to have any health problem/s were given treatment or referred.

\section{RESULTS}

A total of 26 dyads came for baseline interview, and five did not pass the inclusion criteria. Three mothers were less than 18 years old, and two infants were older than six months.

Of the 21 dyads, eight attended the training (Table 2). In addition, five new dyads participated in the training but came too late for baseline interviews. All 13 dyads were interviewed after the training. Two dyads could not participate in the hands-on training (one infant was sick and the other just fed). After seven days, 2 of 13 dyads did not come for the follow-up interview; the mothers/caregivers of said dyads were both full-time housewives.
The average age of the participants was the middle to the late twenties. Most of them were full-time homemakers. The majority of the caregivers were females.

\section{Baseline Perceptions and Experiences of Mothers/ Caregivers}

Of 21 participants interviewed before the training, 18 (86\%) had heard of infant massage; 11 heard about it for the first time from health workers or the researchers. This was one of the first themes derived from the coded responses - that it is perceived as a new concept (Table 3). Six of them did not have an idea how it is done. Other sources of information were their mother/mother-in-law, social media, health facilities, community activities, neighbors, and television. The majority (15) practiced massage introduced by family members, but some (5) do not refer to what they are doing as infant massage. These, and the rest of the themes at baseline, are presented in Table 3.

Before the training, perceptions, and experiences on the following general themes were generated from the participants' responses: 1) general concepts of infant massage, 2) benefits of infant massage, 3) methodologies, materials, and considerations, 4) persons credible to perform infant massage, 5) application/performance of infant massage and 6) intentions to recommend or continue the practice of infant massage, and 7) infant massage as a public health measure.

\section{Perceptions and Experiences of Mothers/ Caregivers after the training}

After the training, the infant's mother remained the most common answer in the post-training interviews (Table 4). Other themes, similar to the ones seen at baseline,

Table 2. Demographic characteristics of participants

\begin{tabular}{lll} 
Characteristics & Pre-training & Post-training \\
Total participants & $\mathrm{N}=21$ & $\mathrm{~N}=13$ \\
\hline Distribution of participants per area & $\begin{array}{l}\text { Commonwealth - 10 } \\
\text { Payatas - 11 }\end{array}$ & $\begin{array}{l}\text { Commonwealth - 6* } \\
\text { Payatas - 7* }\end{array}$ \\
\hline Interview duration, Mean (SD) & 10.9 (3.4) minutes & 6.7 (2.2) minutes \\
\hline Dyads & Mother-infant - 19 & Mother-infant - 12 \\
& $\begin{array}{l}\text { Father-infant - 1 } \\
\text { Caregiver-infant - 1 }\end{array}$ & Father-infant - 1 \\
\hline Mean age (SD) & 25 (7) years & 27 (7) years \\
\hline Number of children & 1 to 4 (median of 2) & 1 to 4 (Median of 2) \\
& NI=1 \\
\hline Occupation & Homemaker - 16 & Homemaker - 7 \\
& Vendor - 2 & Others (6): installer, rug maker, food vendor, \\
Others (3): installer, rug maker, caregiver & food attendant, saleslady, baker \\
\hline Infant sex & Male - 15 & Male - 8 \\
& Female - 6 & Female - 3 \\
\hline Infant age & NI - 2 \\
\hline
\end{tabular}

${ }^{*}$ Commonwealth had one new dyad and Payatas 4 new dyads without baseline interviews. On follow-up, one dyad from each health center did not come for the interview. The mean duration of the remaining 11 interviews was 11 minutes (standard deviation 5.1 minutes). 
Table 3. Themes derived from participants' perceptions and experiences of infant massage before the training

General Perceptions of Infant Massage

1. Infant massage is perceived as a new concept that was just introduced by health workers and researchers at the health center; respondents have no prior or concrete knowledge about the topic.

2. Various informal methods of massaging Infants have been introduced to participants by family members, with no specific aspects and methodologies.

3. The Internet was helpful for more methodological information about infant massage, complementing traditional knowledge and experience.

Benefits of Infant Massage

Before the training, 19 of 21 participants perceived that infant massage is beneficial. All agreed to perform the massage, including the two who did not know if it is valuable.

1. Infant massage is seen to ease and prevent minor ailments and discomfort such as strained muscles and extremities, flatulence (kabag), and muscle knots (lamig sa katawan).

2. The respondents consider infant massage a wellness exercise that helps in bone growth, development, and improved blood circulation.

3. Participants consider infant massage as a way to promote relaxation for their babies.

4. It was considered a way to promote mother-baby bonding and communication (para malaman ang nararamdaman, para malaman kung may karamdaman).

5. Respondents cannot provide justifiable answers to its benefits, but they continuously massage their babies using a method learned from family members.

Methodologies, materials, and considerations

1. The methodology of infant massage known to the respondents consists of gentle manipulations of extremities and other targeted body parts with or without the use of oil.

2. While most of the participants were able to cite some materials and considerations for infant massage, there was a general hesitancy in answering the appropriate age of infant-only three correctly mentioned 'beginning at birth.' Older babies were preferred for fear of massaging small, fragile babies.

3. Some respondents (6) were unaware of how to perform infant massage.
Person credible to perform infant massage

1. Parents, particularly the mother, were generally preferred to give massages to babies.

- Of 21 participants, 9 considered the infant's mother as the best person to give the massage.

- A respondent believed that parents should not rely on other people to massage their babies. Mothers, being the primary caregivers of their babies, can ensure the safety of their babies during the massage.

2. The lack of data on fathers being carers of their babies brought about inconsistencies in their competence in performing infant massage.

- Fathers who are afraid to carry their babies should not perform infant massage.

- Fathers who have soft hands are sometimes better than mothers.

3. The matriarchs of the family on whom the set-up for child care and rearing heavily relies are considered as knowledgeable and competent to perform infant massage

4. Those who are unaware of infant massage rely on healthcare providers, such as doctors, nurses, and barangay health workers, to perform the infant massage

3. Competence, training, ample experience, and familiarity with the baby play a significant role in being considered the best person to perform infant massage.

\section{Application/performance of infant massage}

1. Familial practice and routine dictate that infant massage (perceived as a form of hilot) be continuously done for babies in the family (nakaugalian, turo ng nanay ko).

2. Respondents are optimistic and open in performing infant massage to their babies (All 21 respondents agreed to perform infant massage, including those (2) who said they do not know if it is beneficial. Five have not massaged their babies but are willing to learn how to do it).

3. Fear of hurting their babies (mapilayan, mabalian) can hinder infant massage practice (2 mothers)

4. The majority of the respondents agree to have a fair to good experience with infant massage (15 have massaged their babies before), citing benefits such as improved gross motor functions, mood, and general well-being.

5. Except for a first-time mother who was afraid to hurt her baby, there is a willingness to perform infant massage even among those who have not massaged their babies ( 5 of six respondents).

Intentions and Infant massage as a public health measure

1. Respondents agreed that other carers should know about infant massage given its benefits. Still, some feel that a more qualified person should introduce the concept to the public.

- One will only recommend if she found out infant massage is ok.

- Another will not recommend it because she was not sure if they can do it properly.

- Another was hesitant.

2. If offered to the public, training was widely regarded and welcomed by the respondents as an excellent public health initiative.

- Nineteen were willing to join training to learn about the safe way to do the massage, add to their knowledge, and help babies.

- Only one, an experienced hilot in the community, was not interested. One did not answer.

3. There was a strong clamor for infant massage to be included in the maternal and newborn care program and public health measures of the government (19 participants).

- One preferred infant massage as a private activity. One participant did not answer. 
including the best person who should give infant massage, are shown in Table 4.

All 11 participants interviewed seven days after the training reported having massaged their infants at home. When asked about the experience, participants described the benefits both to themselves and their infants, the process of infant massage (direction or sequence, parts of the body to massage), and the timing or schedule of massage. Table 4 also shows the themes of the participants' experiences.

\section{DISCUSSION}

This qualitative study showed that training could help caregivers of infants 2-6 months old become more knowledgeable about infant massage. The supervised handson session during the training afforded the participants a degree of confidence to try it out on their own in the comforts of their homes.

There was awareness and good perception of infant massage among mothers/caregivers before their formal introduction. Filipino beliefs include massage as one of its integrated folk methods, and this could have contributed to this good perception at baseline. Many have been doing it even before the training. For example, for a common folk disease, "pasma," which may be roughly defined as "hot and cold syndrome," "bilot" or traditional massage is seen as a means to address it. "Lamig" itself was mentioned in the initial interview several times, and "pilay," a folk concept

Table 4. Perceptions and experiences of caregivers after the infant massage training

\section{General perceptions of infant massage}

1. Post-training, respondents showed good comprehension and recall of the basic concepts of infant massage.

2. Infant massage remained to be seen as a traditional practice leading to a deeper understanding of child-rearing and improvement in familial ties.

3. There was a need to address the inconsistent perception regarding considerations and treating illness in infant massage as a prerequisite and form of management.

\section{Methodologies}

1. There was a good recall of the systematic and proper steps of performing infant massage, including the optional use of emollients, as taught during the seminar.

2. Some respondents demonstrated the massage involving gentle traction maneuvers from the head, extremities, and back.

Considerations

1. Respondents believed that the baby's comfort should be the first and foremost consideration in choosing emollients/enablers, mattresses, and the overall mood of the environment.

2. There was a shift in recall and focus from lecture-based contraindications to experience sharing infant massage noted during post-training interviews.

3. There was a need to reiterate constantly that infant massage is safe to start even at birth.

4. Proper hand hygiene was easily recalled by respondents as a fundamental consideration before initiating infant massage, i.e., alcohol may be used, there should be no jewelry, and fingernails should be trimmed.

\section{Perceived competent performers of infant massage}

1. Parents, especially mothers, remained to be preferred by the respondents to give infant massage.

- Intimacy and trust are essential in infant massage, and mothers know their babies well.

- Infant massage can be a way to develop one's relationship with the baby.

- Baby would be more relaxed if their mother were giving the massage.

2. A few participants also included other family members (fathers, grandmothers, anyone in the household) with prior knowledge on performing the infant massage as possible performers apart from the mother.

\section{Perceptions about the infant massage training}

1. The training was considered immensely helpful in understanding infant massage better, especially on the proper method of conducting infant massage - helped six participants to a great extent (sobrang nakatulong) and five participants said that the training helped them a lot (malaking tulong).

2. The session helped the respondents correct their misconceptions of infant massage and improve massage methods, leading to favorable results.

3. The training helped the participants gain confidence in performing infant massage on their own in the comforts of their homes. One participant claimed he is $100 \%$ confident in doing IM. Confidence in performing infant massage ranged from confident (3 participants) to very confident (8 participants).

4. Failure to join the hands-on session did not deter participants from successfully giving their babies massage at home.

5. Printed guides served as aids for participants to try infant massage at home.

6. The formal training, together with the traditional concepts on infant massage, afforded the participants with a more methodologic process of applying it and ensuring the continued practice of infant massage.

7. The use of catchy phrases like 'I Love You,' 'Smile,' and 'Bicycling' to describe specific massage strokes promoted retention and practice.

- The 'I Love You' was a massage stroke performed starting from left-upper abdomen location right under the ribs downwards, then starting from right-upper abdomen exactly beneath the ribs to its opposite point, then down, and starting from right side under stomach upward and continuously following the previous procedures.

- The 'Smile' stroke was the inverted smile applied on the forehead.

- The 'Bicycling' stroke was part of the kinesthetic phase of Field's method of infant massage. They were five one-minute segments involving six passive flexion-extension movements of the arms and legs.

8. The hands-on session served as a way to instill confidence, dispel hesitancy and promote infant massage to other caregivers.

9. Trying out massaging their infants on their own enabled participants to describe the process of infant massage in detail. 
Table 4. Perceptions and experiences of caregivers after the infant massage training (continued)

\section{Experiences during and after massages}

All 11 participants interviewed seven days after the training reported having massaged their infants at home.

1. Infants were observed to be more relaxed and livelier after massages.

2. Gait and flexibilities were improved on the infants with regular massages.

3. Caregivers experienced benefits not only for their infants but for themselves as well-their skills are being honed as they practice, and since the baby is more relaxed, a mother can work.

4. Observed benefits (better sleeping patterns, lessened irritability, more relaxed baby) convinced an initially skeptical father to allow the mother to practice infant massage continually. (importance of the significant other)

5. Observing the benefits on infants during and after massages reinforced a positive perception of infant massage.

6. Massaging her baby herself reinforced her perception that infant massage promotes the mother-baby relationship.

\section{Intentions}

1. There was overwhelming support for conducting infant massage on both occasions after training.

- Immediately after training, all 13 participants agreed to perform infant massage because of perceived benefits for their infants.

- Eleven participants interviewed seven days after agreed to perform infant massage.

- After the training, all 13 participants expressed intent to practice infant massage

2. There was a willingness to undergo further training on infant massage.

- After the training, all 13 participants expressed willingness to participate in future training on infant massage.

- All 11 expressed that they would join another training if the opportunity arose.

3. Participants expressed their intentions to share the knowledge gained in training with other caregivers.

4. Observed benefits of infant massage during and after massages promote intentions to continue practicing infant massage.

Infant massage as a public health measure

The clamor to include infant massage as one of the activities/ programs of their health center was sustained immediately after the training and on follow-up. Immediately after the training, all 13 participants agreed that infant massage training should be one of the activities/programs of the health center. All 11 participants who returned one week after thought that infant massage training should be one of the health center programs.

that can range from inflammation of the limb, damage to ligaments, or even a bone fracture. One mother-participant said that her knowledge of infant massage was passed down by their parents and grandparents, highlighting the role of tradition. Even among those who claimed that they have heard of infant massage for the first time, a theme emerged: they practice a form of massage introduced to them by family members. They do not refer to what they are doing as infant massage, suggesting that infant massage is a method that has to be learned. This could have motivated them to join the training. The excellent fit of infant massage with Filipino culture may be a significant factor facilitating attendance to the training and the cooperation among the participants in this study.

The good initial perception may also be attributed to infant massage educational materials obtained from the Internet and some health facilities. These sources also helped participants learn the methods of infant massage in more detail, as reflected in this theme. The Internet was helpful for more methodological information about infant massage, complementing traditional knowledge and experience. However, the Internet as a source of content for any subject matter is a double-edged sword.

The formal introduction of infant massage to the community can complement traditional and Internet-derived knowledge and skills. This study showed that a half-day training composed of a short lecture, demonstration with a dummy baby, and supervised hands-on session can equip mothers with the knowledge and skills to help massage their babies on their own as reflected in the derived themes from the post-training interviews, such as good recall of the concept of infant massage, massage as a traditional practice, recall and retention of the proper steps of infant massage, and the increased confidence of mother/caregivers in performing it after the training.

Infant massage training can also help stimulate the development of the mothering role, especially for young and first-time mothers. In this study, mothers/caregivers reported a growing attunement to the baby's needs as reflected in the theme of infant massage being a way to develop one's relationship with the baby. Mothers remained to be identified as the best person to massage their babies. For a mother-participant, massaging her baby herself reinforced her perception that infant massage promotes the motherbaby relationship. In a study in Italy, infant massage has been shown to improve the emotional availability ratings of both mothers and infants. Mothers became more sensitive and less intrusive, while babies became more responsive. ${ }^{22}$ Growing confidence in handling the baby may allow the mother to focus on the baby's reactions and the relationship, rather than checking her techniques or being too conscious or careful. Mothers may be less hesitant or pressured and can enjoy the maternal relationship more. Mutual relaxation can also relate easier, together with the effects of oxytocin release in both mother and baby. ${ }^{23}$ It is notable that at the outset of our study, most answers were focused on the longterm benefits of the massage on the baby's growth and development - a more "technical" or "obligatory" dimension of motherhood. After the experience of infant massage, some mothers appeared to be more sensitized to the "relational" role of motherhood. This may be an essential process of development in Filipino mothers.

After seven days, a theme emerged highlighting the benefits of infant massage on the carers themselves Caregivers experienced benefits not only for their infants but for themselves as well-their skills are being honed as they practice. Since the baby is more relaxed, a mother 
can work. This is consistent with a study that showed how infant massage programs increase feelings of competence in parenting and thus decrease parents' levels of stress. ${ }^{14,24}$ Aside from the practical benefits of a more relaxed and calmer baby, it is possible that positive feedback from the baby assures the mother of her effectiveness as a caregiver. Doubts about being a capable parent, a common occurrence among mothers of tiny infants, are allayed. This can lower stressful cognitive states. Focusing on the massage and its sensations may also serve to divert the mother from worries and ruminations. Aside from feelings of well-being, all these also allow greater productivity for mothers. Mothers begin to see the benefits of infant massage not only for the baby but also for themselves. In planning future training, this can be emphasized at the outset and the stated benefits for the baby.

Aside from mothers, other members of the household who know how to perform infant massage - such as fathers, grandparents, aunts - were cited by the participants as persons who can massage their babies. Grandmothers, in particular, perceived to have a lot of experience, are extensively relied upon in caring for infants. Fathers, especially those with soft hands, maybe ideal too, to massage babies. A father initially hesitant towards infant massage was convinced when he saw the benefits to his baby during and after massages by his wife. This emphasizes the role of the significant others in promoting the practice of infant massage. It may be worthwhile to invite these significant others to future training activities on infant massage. Some fathers, like first-time mothers, are hesitant to carry their infants. Infant massage training can be instrumental in assuaging their fears and reservations.

At the end of the training, a medium-size fan illustrating the steps of the two phases of Field's method of infant massage was given to the participants. This was found helpful by the participants as they tried infant massage at home. The use of catchy phrases like 'I Love You,'SSmile,' and 'Bicycling' to describe specific massage strokes promoted retention and practice. The 'I Love You' stroke, a massage for the abdomen, is strictly not part of the Field's method, but the trainer included these since flatulence, and other abdominal discomforts are common.

While the training achieved all these, this study also showed a need to address the inconsistent perceptions that "ill infants should not be massaged." and "massage can be a remedy for simple illnesses". Also, there is a need to reiterate that infant massage is safe to start even at birth. Considering the fragile nature of infants, a mother believed that babies should be at least three months old. Contraindications can also be more emphasized. Participants were able to enumerate contraindications immediately after the training. Still, on follow-up (7 days after), their answers focused more on their experience of massaging their infants independently.

Ideally, the training of mothers/caregivers should last five to six weeks, as prescribed by the International Association of Infant Massage (IAIM). ${ }^{25}$ However, this was not deemed feasible given the busy schedule of mothers/caregivers, particularly those taking care of more than one child. The cost of this extensive training may also not be realistic, given the resources and existing programs of the city health department. Our study's training was a half-day training that included a lecture on infant massage with a demonstration using a dummy baby, followed by a supervised hands-on session. Despite this short duration, participants were able to gain knowledge and experience on infant massage. The health centers may do additional training activities to reinforce these gains. The majority of the participants expressed interest in attending future training activities on infant massage.

Social support may also be stressed in future training activities. According to IAIM, infant massage can empower parents through opportunities to join a group of like-minded parents and share parental experiences without being judged, among others. ${ }^{26}$ While social support was not emphasized in this study, it is deemed possible, given the generally friendly nature of Filipinos.

\section{Conclusion}

There was a positive perception of infant massage among mothers and caregivers of infants 2-6 months old, whether they had prior knowledge of it or they considered it as a new concept. The sharing of information and the training given enhanced this. Participants showed good reception and retention of infant massage's basic concepts and process and improved their confidence in handling their babies and massaging them.

\section{Limitations and Recommendations}

The study had some methodological limitations. Some participants were lost in the follow-up periods, who may have been mothers/caregivers who had negative experiences with infant massage and represented alternative perceptions. Open questions were used to elicit a wide range of answers. However, some participants' natural shyness could have been a hindrance. Social desirability bias may have come into play in the participant responses.

Future infant massage training activities/programs may benefit from these improvements: 1) focus not only on benefits to infants but also on maternal and familial benefits, 2) emphasize that while massage may be done to ease discomfort and minor illnesses, it is vital to consider the contraindications 3) complement the interviews with focus group discussions (facilitators and interviewers must not be part of training organizers), 4) have a communitybuilding component for peer support, 5) invite other family members, like the fathers, to allay hesitations, 6) intentionally include teenage mothers and infants younger than two months and older than six months old, emphasizing that it is safe to start infant massage even at birth 7) strengthen cooperation with providers and CHWs of health centers to improve participation in after-training feedback sessions and 8) to better document outcomes, a monitoring and evaluation plan can be built into the program. 


\section{Acknowledgments}

This study would not have been possible without the exceptional support of the following institutions and individuals: the University of the Philippines Manila Research Ethics Board (UP Manila REB), for the review and approval of the protocol and study oversight; administrators and staff of the Foundation for the Advancement of Clinical Epidemiology, Inc. for administering the study logistics; the Philippine League of Government and Private Midwives, Inc. (PLGPMI) for the expertise on imparting the proper method of infant massage to mothers/caregivers; and Johnson and Johnson Philippines, Inc., for sponsoring the study.

This study would also not be possible without the partnership of the local government of Quezon City (QC) led by then-Mayor Herbert M. Bautista and the University of the Philippines Manila headed by Chancellor Carmencita D. Padilla. The authors are grateful to the QC Legal Department, the QC Health Department, and the UP Manila Legal Office for facilitating this partnership.

Key to the conduct of the study is the support of the administrators and staff of the QC Health Department, the health administrators, providers, and CHWs of Commonwealth Main and Payatas B health centers. Their advice and assistance in recruiting, screening, preparing for, and conducting the training were vital.

We are also grateful to the barangay officials; their support is essential in this community-based study. We also thank the individuals who assisted us in the registration and interviews of the participants. Finally, we extend our sincerest thanks to the mothers, caregivers, and infants who actively participated in the study.

\section{Statement of Authorship}

All authors approved the final version submitted and have participated in the data analysis and writing of the manuscript. Cordero, Tolosa, Lubat, Llanes and Hermoso were involved in the conceptualization, coordination and data collection.

\section{Author Disclosure}

All authors declared no conflicts of interest.

\section{Funding Source}

This study was funded by Johnson and Johnson Philippines, Inc.

\section{REFERENCES}

1. Porter SJ. The Use of Massage for Neonates Requiring Special Care. Complement Ther Nurs Midwifery. 1996; 2(4), 93-6

2. Vickers A, Ohlsson J, Lacy A, Horsley A. Massage for Promoting Growth and Development of Preterm and/or Low Birth-weight Infants. Cochrane Database Syst Rev. 2004; 2004(2):CD000390. doi: 10.1002/14651858.CD000390.pub2. PMID 15106151; PMCID: PMC6956667.

3. Gunnar MR. Quality of Early Care and Buffering of Neuroendocrine Stress Reactions: Potential Effects on the Developing Human Brain. Prev Med. 1998 Mar-Apr;27(2):208-11.
4. Field T, Schanberg S, Davalos M, Malphurs J. Massage with Oil has More Positive Effects on Normal Infants. Journal of Prenatal and Perinatal Psychology and Health. 1996;11(2): 75-80.

5. Uvnäs-Moberg K, Widström AM, Marchini G, Winberg J. Release of GI Hormones in Mother and Infant by Sensory Stimulation. Acta Paediatr Scand. 1987 Nov;76(6):851-60.

6. Ferber SG, Laudon M, Kuint J, Weller A, Zisapel N. Massage Therapy by Mothers Enhances the Adjustment of Circadian Rhythms to the Nocturnal Period in Full-term Infants. J Dev Behav Pediatr. 2002 Dec;23(6):410-5.

7. Cifra H, Sancho M. Touch Research in the Philippines. UP Manila Journal. 2003; (8) 1-11.

8. Bennett C, Underdown A, Barlow J. Massage for Promoting Mental and Physical Health in Typically Developing Infants under the Age of Six Months. Cochrane Database Syst Rev. 2013 Apr 30; (4):CD005038.

9. Agarwal KN, Gupta A, Pushkarna R, Bhargava SK, Faridi MM, Prabhu MK. Effects of Massage \& Use of Oil on Growth, Blood Flow \& Sleep Pattern in Infants. Indian J Med Res. 2000 Dec;112:212-7.

10. Jing J, Li X, Feng L, Wu Q,Wang Z, Zeng S, Gu Y, Cai X. Massage and Motion Training for Growth and Development of Infants. World J Pediatr. 2007;3(4):295-9.

11. Underdown A, Barlow J. Interventions to Support Early Relationships: Mechanisms Identified within Infant Massage Programmes. Community Practitioner. 2011Jan; 84(4), 21.

12. Mayo Clinic Staff. Infant Massage: Understanding This Soothing Therapy; Looking for Ways to Relax and Bond with Your Baby? Know When and How to Give an Infant Massage [Internet]. [cited 2021 May 4]. Available from: https://www.mayoclinic.org/healthy-lifestyle/ infant-and-toddler-health/in-depth/infant-massage/art-20047151

13. Nurturing Touch Therapeutic Play Clinic Located in Makati City, National Capital Region [Internet]. [cited 2021 June 30]. Available from: (https://mobile.facebook.com/profile.php?id=381698425229792).

14. Vicente S, Veríssimo M, Diniz E. Infant Massage Improves Attitudes toward Childbearing, Maternal Satisfaction and Pleasure in Parenting. Infant Behav Dev. 2017 Nov;49:114-119.

15. Midtsund A, Litland A, Hjälmhult E. Mothers' Experiences Learning and Performing Infant Massage-A Qualitative Study. J Clin Nurs. 2019 Feb;28(3-4):489-498.

16. Field TM, Schanberg SM, Scafidi F, Bauer CR, Vega-Lahr N, Garcia R, Nystrom J, Kuhn CM. Tactile/kinesthetic Stimulation Effects on Preterm Neonates. Pediatrics. 1986 May;77(5):654-8.

17. Ferber SG, Kuint J, Weller A, Feldman R, Dollberg S, Arbel E, Kohelet D. Massage Therapy by Mothers and Trained Professionals Enhances Weight Gain in Preterm Infants. Early Hum Dev. 2002 Apr;67 (1-2): 37-45.

18. Field T, Diego MA, Hernandez-Reif M, Deeds O, Figuereido B. Moderate versus Light Pressure Massage Therapy Leads to Greater Weight Gain in Preterm Infants. Infant Behav Dev. 2006 Dec;29(4):574-8.

19. Abdallah B, Badr LK, Hawwari M. The Efficacy of Massage on Short and Long Term Outcomes in Preterm Infants. Infant Behav Dev. 2013 Dec;36(4):662-9.

20. Beider S,Mahrer NE, Gold JI.Pediatric Massage Therapy: An Overview for Clinicians. Pediatr Clin North Am. 2007 Dec;54(6):1025-41

21. Field T. Massage Therapy. Complementary Alternat Med. 2002; 86: 168-171.

22. Porreca A, Parolin M, Bozza G, Freato S, Simounelli A. Infant Massage and Quality of Early Mother-infant Interactions: Are There Associations with Maternal Psychological Wellbeing, Marital Quality, and Social Support? Front Psychol. 2017 Jan 17; 7:2049.

23. Glover V, Onozawa K, Hodgkinson A. Benefits of Infant Massage for Mothers with Postnatal Depression. Semin Neonatol. 2002 Dec;7(6): 495-500.

24. Beyer K, Strauss L. Infant Massage Programs May Assist in Decreasing Parental Perceived Stress Levels in New Parents. Occup Ther Health Care. 2003; 16(4). 53.

25. International Association for Infant Massage (n.d.) FAQs for Parents [Internet]. [cited $2021 \mathrm{Jan}$ ]. Available from: https://www.iaim.net/ massage-your-baby/faqs-for-parents/

26. Simpson R. Baby Massage Classes and the Work of the International Association of Infant Massage. Complement Ther Nurs Midwifery. 2001 Feb; 7(1): 25. 